\title{
The Impact of Disaggregated Electricity Generation on Economic Growth: MENA Countries (2005-2014)
}

\author{
Haidy Amer \\ School of Business, Arab Academy for Science, Technology and Maritime Transport, Alexandria, Egypt \\ Email address: \\ r02hma14@abdn.ac.uk \\ To cite this article: \\ Haidy Amer. The Impact of Disaggregated Electricity Generation on Economic Growth: MENA Countries (2005-2014). International \\ Journal of Economy, Energy and Environment. Vol. 4, No. 3, 2019, pp. 41-55. doi: 10.11648/j.ijeee.20190403.11
}

Received: May 23, 2019; Accepted: July 5, 2019; Published: July 31, 2019

\begin{abstract}
This paper examines the impact of electricity generation on economic growth using data for a panel of 12 countries elected from MENA region over the period 2005-2014. The paper contributes to the literature in several ways. First, in contrast to the present literature which focuses on electricity consumption, this paper focuses on the impact of electricity generation on economic growth. This is because not all of the electricity that is generated is eventually consumed, due to dissemination losses, stolen power and the other so called "non-technical losses" which makes it necessary to examine the impact of electricity generation on economic growth. Second, we disaggregate the influence of total electricity generation on growth into renewable and non-renewable effects. The fact that the renewable electricity is gaining a great importance and the global care for its implementation makes it necessary to study its effect in the MENA region given the great potential of these sources in the region. Never the less, the effect of such sources of electricity on the economic growth is being investigated while at the same time using control variables like trade openness, financial development and $\mathrm{CO}_{2}$ emissions. Third, the study is different from previous studies in focusing on granger causality and/or cointegration by estimating the effect of electricity generation on growth using the System Generalized Method of Moments(GMM). GMM is being used given that electricity generation and many of the other regressors in the model may be jointly determined with GDP growth and thus be treated as endogenous variables a matter that can be handled by the GMM. Our results indicate a strong negative and statistically significant relationship between renewable and non-renewable electricity generation indicating the possibility of substitution between the two sources in these selected countries, yet with different impact on the economic growth.
\end{abstract}

Keywords: Renewable Electricity Generation, Fossil Fuel, Economic Growth

\section{Introduction}

Energy is divided in two sources which are the renewables and non-renewable energy sources. The former refers to the kind of energy generated from natural resources such as sunlight, wind, rain, tides and geothermal heat. The latter involves earth minerals and particularly fossil fuels (coal, petroleum, natural gas). Existing research recognizes that fossil fuels prevails to be the nerve of the world's energy system constituting about $81 \%$ of all primary energy in the world while geothermal, wind, solar or other alternative energy sources makes Only $0.8 \%$ of the world's primary energy.

The demand for fossil fuel energy has been expanding at a high rate causing a lot of environmental problems with the controversy here being that increasing the non-renewable energy consumption while increases economic growth will at the same time increase $\mathrm{CO}_{2}$ emissions. These emissions are considered to be the main player in the global warming problem. One important feature of energy that has been gaining attention recently is the influence of electricity on economic growth in general and how it affect environment.

Regarding MENA region, it represents the second most polluted region after South Asia and the highest $\mathrm{CO}_{2}$ producer per dollar of output. MENA region is facing many challenges toward the aims of mitigating climate change and air pollution being heavily dependent on the fossil fuels. What makes the challenges even worse is the heavy subsidies on petroleum products making them easy accessible and thus encouraging more wasteful use of fossil energy. These subsidies work as an obstacle to the investments in clean technology.

The MENA region use of renewable energy sources in the 
future is inevitable as these countries are facing many challenges among them are; (a) high rates of energy intensity where according to a report of British Petroleum, it is mentioned that the MENA countries are almost twice as energy intensive as the world's average, (b) the MENA region is considered to be the second emitter of the $\mathrm{CO}_{2}$ emissions after south Asia, one of the main reasons for increased GHG emissions from MENA energy sector is the low efficiency of energy resource consumption. The energy intensity, energy use per unit of GDP, is very high which raises the GHG emissions. Actually, from 1981-2009 every region in the world had negative energy intensity growth rates except for the MENA region, according to World Bank data. (c) these countries are facing high energy demand stemming from increasing energy demand across the end-use sectors: in the residential sector through the high use of air conditioning and cooling units; in the transportation sector through rising vehicle ownership; and in the industrial sector from greater industrial activity, hydrocarbon production and refining, and energy-intensive desalination plants. Nevertheless, the high population growth rates with high ambitious economic growth rates also increase energy demand. All of these reasons should push forward to the increase use of renewables given that these countries are endowed with such natural resources.

According to the World Bank, The Middle East and North Africa (MENA) region has about $57 \%$ of the world's proven oil reserves and $41 \%$ of proven natural gas resources ${ }^{1}$. Considerable differences do exist in the energy sector in the MENA region with regard to individual countries. Most of the countries in the MENA region suffer from inefficient use of supply, high energy intensity in energy use, increasing environmental problems, and a rapidly increasing burden on government finances. The most important challenge these countries face is how to cope with the high oil prices while financing the rapidly growing energy demand in general and electricity in particular.

In addition, previous research has established the fact that trade openness and financial development beside energy consumption and economic growth are very important factors in explaining the changes in carbon emissions.

More expressly, the trade openness impact can be divided into three effects, scale effect, composition effect and technique effect. The scale effect means that more trade leads to, higher production, higher energy consumption and consequently higher pollution. Composition effect, means that a country increase trade in the goods of its comparative advantage will lead to increase or a decrease in pollution depending on whether this good is being produced in energy intensive sectors or not. Technique effect, means that if the countries are adapting environmentally friendly technologies in producing goods, this could lead to environmental improvements. Thus, trade openness is considered to be a key input in the process of economic growth. Hence, the inclusion of trade opens in the energy growth context should lead to some more rational implications.

As for the financial development, and according to Sadorsky, P., (2010) [41], financial development can affect energy consumption, energy efficiency and economic growth. Firstly, it can affect energy consumption by facilitating borrowing money for both consumers and producers to purchase more home electrical appliances, machines, automobiles and houses. But at the same time, this might harm environment and increase $\mathrm{CO}_{2}$ emissions through the growing industrial sector. Secondly, financial development can also improve energy efficiency by lending money to support the development of energy savings industries through firms that utilize environment friendly technology that emits less $\mathrm{CO}_{2}$ emissions. Finally, growing financial markets can speed up economic growth through attracting local and foreign investors. Thus, financial development not only influences energy consumption, but also affects economic growth. Literally speaking, estimated results may be biased if financial development is omitted from the energy growth framework. Hence, including the financial development should lead to more rational results.

Accordingly, and to the researcher knowledge, there is no study that has been published to investigate the causal relationship between all of the forehead mentioned variables. Doing so, this paper should add to the literature a comparison between the impacts of both renewable and fossil fuel electricity generation vitality utilization on imperative economic variables through a dynamic interrelationship.

Thus and in conclusion, the purpose of this paper is to investigate the impact of renewable and nonrenewable electricity generation on economic growth using data for a panel of 12 countries from MENA region over the period 2005-2014. The paper makes several contributions to the literature.

First, while previous papers have focused on the impact of energy consumption on economic growth, this paper focuses on the effect of electricity generation on growth. In fact, not all of the electricity generated in the country is eventually consumed due to transmission and distribution losses, as well as theft. According to Depuru et al. (2011) [12], he reported that global transmission and distribution electricity losses are estimated to exceed the total generation capacity of the United Kingdom, Germany, and France, which translates to a loss of more than $\$ 25$ billion annually. These losses occur due to transmission, distribution, and theft, accompanied with the fact that some of the generated electricity is being exported rather than consumed. These facts point out that the impact of electricity generation on economic growth may differ from that of electricity consumption.

In MENA region, the following countries have exported electricity represented as a per cent of the total world electricity as the follows: Turkey $(0.3 \%$ of total electricity exports), Iran (0.2\%), Algeria (0.1\%), Jordan (0.02\%), Egypt and Morocco share the same percent $(0.001 \%)^{2}$.

Second, and perhaps the most important contribution of 
the paper, is that this study deviates from previous studies throughout employing granger causality and cointegration approaches by estimating the effect of electricity generation on growth using the SYS- GMM estimator. Given that electricity generation and many of the other regressors in the model under examination may be mutually determined by GDP growth, the System GMM approach is appropriate in dealing with such endogeneity issues. Nevertheless, the validity of the SYS-GMM assumption for the use of the instruments are tested using the Hansen test of over identification.

Third, the study further highlights on the impacts of electricity generation by disaggregating total electricity generation into separate measures of renewable and nonrenewable electricity generation, while controlling for other variables like $\mathrm{CO}_{2}$ emissions per capita, trade openness and financial development. With increasing pursuit of energy security, technological advances, the falling costs of renewables, and the movement to exploit renewable energy sources for electrification, there is need to study not only the impact of traditional sources of electricity but renewable sources, as well.

\section{Literature Review}

A large number of studies examined the energy -economic growth-environment connection. To set it clear, we divide the literature review in three groups. Firstly, the one concerned with the relationship between energy consumption in its aggregate form with economic growth and environment. The second group is concerned with only the relationship between renewable energy consumption, economic growth and environment. The third and last group is concerned with the relationship between the disaggregated energy variables, economic growth, environment and other variables as well.

\subsection{The Relationship Between Aggregate Energy Consumption, Economic Growth and Environment}

The first group include studies of Apergis et al. (2010) [2] and Halicioglu, F., (2009) [19] where both of them found a positive relationship between energy consumption as a whole and the $\mathrm{CO}_{2}$ emissions. Halicioglu, F., (2009) [19] found that the $\mathrm{CO}_{2}$ emission are being determined by energy consumption, income and foreign trade. In addition, Arouri et al. (2012) [4] found a remarkable positive significant impact of energy consumption in its aggregate form $\mathrm{CO}_{2}$ emissions. Muhammad, B., (2019) [31] analyzed the effect of economic growth, energy consumption and $\mathrm{CO}_{2}$ emissions on each other for a panel of 68 countries including MENA region. The results indicated that economic growth declines with increase in energy consumption and are the $\mathrm{CO}_{2}$ emissions for the period of (2001-2017). Also, Gorus, M.S. and Aydin, M., (2019) [16] for a panel of MENA region over the period (1975-2014) found that according to the panel causality test results, energy conservation policies do not have an adverse effect on economic growth both in the short- and intermediate-run while their effects are negative in the long run.

\subsection{The Relationship Between Renewable Energy Consumption, Economic Growth and Environment}

The second group include empirical studies that focused only on the renewable energy variable and its relation to the economic growth and $\mathrm{CO}_{2}$ emissions with the possible inclusion of other variables like trade openness and globalization. Of these studies are, Boluk et al. (2014)[7] using the Autoregressive Distributed Lag (ARDL) approach found a negative relationship between renewable electricity consumption and $\mathrm{CO}_{2}$ emissions in the short run with the recommendations being made to draw the attention to the importance of renewable energy sources in controlling emissions in Turkey. Also, Sebri et al. (2014)[42] Using the ARDL and VAR approach found a bi-directional causality between economic growth and renewable energy consumption pointing out to the role of renewable energy in stimulating economic growth in BRICS countries.

Leitao et al. (2014) [28] found a positive relationship between carbon dioxide emissions and renewable energy and economic growth, in addition to unidirectional causality between renewable energy and economic growth. Fahrani et al. (2012) [14] found that in the short run, only a unidirectional causality running from renewable energy consumption to $\mathrm{CO}_{2}$ emissions. The results pointed out that MENA countries still lack the appropriate policy that can control pricing renewable energy while taking into consideration the economic growth stability.

Apergis et al. (2010) [2] examined the relationship between renewable energy consumption and economic growth over the period 1985-2005 using a panel cointegration and error correction model. A long-run equilibrium relationship between real GDP, renewable energy Consumption, real gross fixed capital formation, and the labor force has been indicated. Based on the results, they concluded that the expansion of renewable energy should reduce dependence on foreign energy sources and curtail the long-run environmental degradation associated with carbon emissions.

Kahia et al. (2019) [26] investigated the influence of renewable energy consumption, economic growth, foreign direct investment inflows and trade on carbon dioxide emissions in 12 MENA countries for the period of (19802012). The results from Granger causality test disclosed a bidirectional causality relationship between the mentioned variables supporting the feedback hypothesis. The findings revealed that economic growth leads to environmental degradation while renewable energy, international trade and foreign direct investment inflows lead to a reduction in carbon dioxide emissions.

\subsection{The Relationship Between the Disaggregated Energy Variables, Economic Growth, and Environment}

The third group include studies that focused on disaggregated energy variables, economic growth and $\mathrm{CO}_{2}$ 
emissions with the inclusion of other variables also like trade openness and urbanization. Ben Jebli et al. (2013) [6] realized that in the long-run, non-renewable energy and trade positively affect $\mathrm{CO}_{2}$ emissions, whereas renewable energy negatively affects $\mathrm{CO}_{2}$ emission. Arouri et al. (2012) [4] also observed a negative relationship between renewable energy consumption and $\mathrm{CO}_{2}$ emissions while the non-renewable energy consumption affects it positively. Muhammad et al. (2011) [32] proved that efforts done to substitute renewable energy consumption for nonrenewable energy consumption resulted in a lower level of $\mathrm{CO}_{2}$ emissions.

By the same manner, Aissa et al. (2014) [1] perceived that in the long-run, per capita GDP and per capita non-renewable energy consumption is found to positively affect the per capita $\mathrm{CO}_{2}$ emissions. In addition, the long-run estimates disclosed that the square of per capita GDP, per capita renewable energy consumption, and per capita real exports and imports negatively impact per capita $\mathrm{CO}_{2}$ emissions. Therefore, global warming can be defeated by more trade openness and more use of renewable energy.

Last but not least, Tiwari A.K., (2011) [47] pointed out to a negative impact of NREs on the GDP growth rate while a positive impact on $\mathrm{CO}_{2}$ emissions. On the contrary, The RES positively affects the GDP growth rate. Hence, recommendations were made for reducing the NREs for the benefit of economic growth and environmental degradation in the Europe and Eurasian countries. Wesseh et al. (2012) [48] detected the presence of a unidirectional causality running from renewable and non-renewable electricity consumption and output to $\mathrm{CO}_{2}$ emissions in the short run while in the long-run, they found a bidirectional causality between electricity consumption (renewable and nonrenewable) and $\mathrm{CO}_{2}$ emissions.

All of these studies almost concluded the same conclusion regarding the negative effect of renewable energy consumption on $\mathrm{CO}_{2}$ emissions and the positive effect of non-renewable energy it with causality running from renewable energy to real GDP showing the power of this source of energy in stimulating the economic growth if substituted for fossil fuels.

In sum, all the previous studies had drawn the attention to the importance of renewable energy consumption in both stimulating more economic growth while compacting $\mathrm{CO}_{2}$ emissions at the same time. This conclusion is importance as it points out to the fact that applying conservative policies should not affect economic growth. The present study should show shed the light on the relationship between the energy variables and economic growth in addition to the trade openness and financial development.

\section{Materials and Methods}

\subsection{Data}

The empirical analysis is based on annual time series data of twelve MENA region countries over the period of 20052014. Data for all of the variables are taken from World
Development Indicators (WDI) for the World Bank and the U.S. Energy Information Administration (EIA). In this study, the relationship between renewable and non-renewable electricity generation (RE, $\mathrm{NRE}$ ), $\mathrm{CO}_{2}$ emissions per capita $\left(\mathrm{PCO}_{2}\right)$, real gross domestic product per capita (PRGDP), trade openness (TO) and financial development (FD) is investigated. The data used is all transformed into logarithmic for ease of interpretation and to have the coefficients interpreted as elasticities with respect to the dependent variable. The CPI $(2010=100)$ index is used to capture the real values of the per capita gross domestic product. The 12 countries are as the following: Algeria, Egypt, Iran, Iraq, Israel, Jordon, Lebanon, Morocco, Turkey, Tunisia, Sudan and Libya.

In this paper, renewable energy is measured as a net generation of electricity from renewable sources and it is measured in absolute terms not as a percentage. The term generation refers to the amount of electricity a generator produces over a specific period of time. Generation data consists of both utility and nonutility sources. According to EIA, renewables include electricity generated from wind, solar photovoltaic, solar thermal, geothermal, wood and wood-derived fuels, landfill gas, biogenic municipal solid waste, conventional hydroelectric plants, other waste and biomass. As for fossil fuel, it consists of the total fossil fuels electricity net generation from coal, petroleum, and natural gas and is measured in billion kilowatt hours.

The $\mathrm{CO}_{2}$ emissions per capita, real gross domestic product per capita, financial development and trade openness have been obtained from the World Bank indicators given that all the data was available. $\mathrm{CO}_{2}$ emissions per capita refers to emissions stemming from the burning of fossil fuels and the manufacture of cement. This includes carbon dioxide produced during consumption of solid, liquid, and gas fuels and gas flaring which stem from the burning of fossil fuels and the manufacture of cement.

GDP per capita (constant 2010 US\$), is gross domestic product divided by midyear population. GDP is the sum of gross value added by all resident producers in the economy in addition to any product taxes and minus any subsidies not included in the value of the products. It is calculated without making deductions of depreciation of fabricated assets. Data is in 2010 U.S. dollars.

Financial development is measured as domestic credit to private sector (\% of GDP) by banks which refers to financial resources provided to the private sector by other depository corporations, such as through loans, purchases of non-equity securities, and trade credits and other accounts receivable, that establish a claim for repayment. For some countries these claims include credit to public enterprises. Finally, Trade (\% of GDP) is the sum of exports and imports of goods and services measured as a share of gross domestic product.

The study uses the consumer price index of 2010. Consumer price index reflects changes in the cost, to the average consumer, of acquiring a basket of goods and services that may be fixed or changed at specified intervals. 


\subsection{Descriptive Statistics and Econometric Methodology}

In this paper, the methodology will start with some descriptive statistics for the model variables as shown in table 1. After that the paper will continue to implement panel unit root analysis, panel cointegration analysis, panel VAR/VECM and ending with panel causality analysis. All these tests will be conducted after examining for the presence or absence of cross section correlation between the panel units.

\subsubsection{Panel Unit Root Analysis}

Before conducting any unit root tests, we have first to determine the number of lags used for each variable which is done according to an information selection criterion. Since this paper is planned and designed to depend on the GMM methodology in estimating PVAR/PVEC model, then it makes sense to benefit from the GMM model selection criteria it provides.

According to table 1, it can be seen that all of the variables except trade openness don't have normal distribution with a Jarque-Bera probability less than $1 \%$. However, one of the advantages of using the GMM in estimating the PVAR is dealing with non-normal distributed variables as the GMM methodology obeys the central limit theorem.

Considering the appropriate lag selection, in 2001, Andrews and Lu (2001) [3], suggested a consistent moment and model selection criteria (MMSC) for the GMM models that are based on Hansen's (1982) J - statistic [20] of overidentifying restrictions. The model and moment selection criteria (MMSC) is compatible and able of choosing the right model and moments for GMM estimation under the probability of having the sample size greater than the time series. Applying Andrews and Lu's MMSC to the GMM estimator, their proposed criteria choose the pair of vectors $(p, q)$ that minimizes

$$
\operatorname{MMSC}_{B I C, n}(k, p, q)=j_{n}\left(k^{2} p, k^{2} q\right)-(|q|-|p|) k^{2} \ln (n)(1)
$$

Where $J n(k, p, q)$ is the $J$ statistic of over-identifying restriction for a $k$-variate panel VAR of order $p$ and moment conditions based on $q$ lags of the dependent variables with sample size $n$. Thus the MMSC helps in both selecting not only the most suitable number of lags $(p)$ to be used in the PVAR specification but it allows also the selection of the appropriate number of instruments $(q)$ needed for the model regressors.

Table 1. Descriptive Statistics.

\begin{tabular}{lllllll}
\hline & PRGDP & PCO $_{2}$ & NRE & RE & FD & TO \\
\hline Mean & 7398.421 & 4.226215 & 58.20169 & 7.455898 & 72.42035 \\
Maximum & 32661.29 & 10.04375 & 240.5178 & 68.10100 & 93.49260 \\
Minimum & 1189.961 & 0.273951 & 1.219180 & 0.000000 & 1.551835 \\
Std. Dev. & 7582.191 & 2.684321 & 62.55768 & 13.90914 & 26.99925 \\
Jarque-Bera & 203.1484 & 10.99313 & 37.06606 & 388.0906 & 8.804740 \\
Probability & 0.000000 & 0.004101 & 0.000000 & 0.000000 & 0.012248 \\
\hline
\end{tabular}

Notes: Author's calculation

Table 2. PVAR Lag Order Selection Criterion.

\begin{tabular}{lllll}
\hline Lags & CD & J & J P-VALUE & MBIC \\
\hline 1 & .623538 & 82.38163 & .188972 & $-254.7318^{*}$ \\
2 & .8495319 & 41.51064 & .2429977 & -127.0461 \\
\hline
\end{tabular}

Notes: *indicates the lag order selection $(p)$ of only one lag for the PVAR order.

According to table 2, although choosing one lag as an instrument means to have just identified system but due to having serial correlation problem then, either two or three lags at maximum have to be chosen as moment conditions to be used. This is because in order to apply the SYS-GMM correctly, it assumes that all of the model variables before any transformation are free form any serial correlation and if it exists then a simple remedy is to introduce further lags and will still remain as valid instruments. Thus, the end result is choosing three lags not two although fears from proliferation do exist.

Having applied a serial correlation test for the variables in level, a problem of serial correlations have been detected and thus the solution was to add more moment conditions to end up with three lags as instruments. The Wooldridge test for autocorrelation rejected the null hypothesis at the $5 \%$ level of significance $(\mathrm{P} .=0.0069)$. Finally, PVAR of first order is going to be applied having the MBIC criterion gave the lowest smallest value for only one lag.

Secondly, it is becoming now important to check for the presence of cross section dependence among the panel units. The presence of cross sectional correlation of errors in the panel is likely to be common now and thus disregarding it can have some serious outcomes like affecting the unbiasedness and consistency of the standard panel estimates leading to wrong inferences.

Consider the following panel data model

$$
\begin{gathered}
y_{i t}=\beta_{i}{ }^{\prime} X_{i t}+u_{i t} \\
i=1,2, \ldots ., N, t=1,2, \ldots ., T
\end{gathered}
$$

Where $i$ indexes the cross-section dimension and $t$ the time series dimension, $X_{i t}$ is a $\mathrm{k} \times 1$ vector of regressors. The coefficients, $\beta_{i}$ are allowed to vary across $i$. For each $i, u_{i t} \sim$ IID $\left(0, \sigma^{2}{ }_{\mu i}\right)$, for all $\mathrm{t}$, although they could be cross-sectionally correlated. Moreover, Pesaran (2004) [37] calls attention to that while this specification has cross-section specific coefficients, the depicted beneath are likewise can be also applicable to the more restrictive fixed and random effects models.

The general null hypothesis of no cross-section 
dependence can be expressed in terms of the correlations between the disturbances in different cross-section units:

$$
H_{0}: \rho_{i j=} \rho_{j i}=\operatorname{Corr}\left(u_{i t}, u_{j t}\right)=0 \text { For } i \neq j
$$

For balanced panels, $\rho_{i j}$ is the product-moment correlation coefficients of the residuals, precisely:

$$
\hat{\rho}_{i j}=\hat{\rho}_{j i}=\frac{\sum_{t=1}^{T} e_{i t} e_{j t}}{\left(\sum_{t=1}^{T} e_{i t^{2}}\right)^{1 / 2}\left(\sum_{t=1}^{T} e_{j t^{2}}\right)^{1 / 2}}
$$

And $e_{i t}$ is the Ordinary Least Squares (OLS) estimate of $u_{i t}$ defined by;

$$
e_{i t}=y_{i t}-\hat{\beta}_{i}{ }^{\prime} X_{i t}
$$

Where with $\hat{\beta}_{i}$ being the estimates of $\beta_{i}$ computed using the OLS regression of $y_{i t}$ on $X_{i t}$ for each $i$ separately.

Pesaran (2004) [37] cross-sectional dependency (CD) is calculated as the following;

$$
C D=\sqrt{\frac{2 T}{N(N-1)}}\left[\sum_{i=1}^{N-1} \sum_{j=i+1}^{N} \hat{\rho}_{i j}\right] \stackrel{d}{\rightarrow} N(0,1)
$$

Pesaran's (2004) [37] cross-sectional dependence $\left(\mathrm{CD}_{\mathrm{LM}}\right.$ test) test that is valid when $T<N$ and can be used with balanced and unbalanced panels including homogenous/heterogeneous dynamic models as well as nonstationary models. Thus, the Pesaran's (2004) [37] is the one to be used in this paper due to having short panels.

The CD test is thus applied on the analyzed variables to examine whether or not each time series is cross sectional independent or not. This is done through setting a panel ADF equation for every variable in the model to be tested and thus six $\mathrm{ADF}$ equations for all of the six variables will be set for examination. This is done through setting each of variables as a dependent one and to be run over its lagged and differenced lag values as the follows;

$$
\Delta y_{i t}=\gamma y_{i, t-1}+\sum_{j=1}^{p} \delta_{j} \Delta y_{i, t-j}+\alpha+\beta t+\varepsilon_{i t}
$$

Where $(\beta)$ the coefficient on a time trend, $(\alpha)$ is the constant and $(p)$ is the lag order of the autoregressive process. This means that the number of lags should to be firstly correctly determined.

Table 3. The Pesaran CD (2004) Test.

\begin{tabular}{lll}
\hline & Intercept & \\
\hline Variables & LM statistic & P-value \\
\hline LPRGDP $_{\mathrm{LPCO}_{2}}$ & 2.657 & 0.0079 \\
$\mathrm{LNRE}$ & -.598 & $0.5499^{* *}$ \\
LRE & 1.003 & $0.3159^{* *}$ \\
LFD & 2.268 & $0.0233^{* * *}$ \\
LTO & 1.315 & $0.1884^{* *}$ \\
\hline
\end{tabular}

Notes: (1) The Pesaran (2004) test has been applied through the command "xtcsi" in Stata. (2) ***, ** and * denotes statistical significance at the $1 \%$, $5 \%$ and $10 \%$ levels respectively. (3) The null hypothesis is cross section independence.

According to table 3, it can be inferred that four out of the six variables don't suffer from cross section dependence problem and thus first-generation tests for checking the stationarity properties of the variables and co-integration should be applied.

Returning back to the unit root tests, they include among others, Levin, Lin and Chu's test (2002) [29], Harris-Tsavalis test (1999) [21], Im, Pesaran and Shin (2003) [23] and the Fisher-type test proposed first by Maddala and Wu (1999) [30]. These types of tests are all based on the assumption of having the individual time series in the panel being crosssectional independently distributed, where a large amount of co-movements can be found between the economic variables. These kinds of tests can assume either a homogenous AR coefficient of the lagged dependent variable or a heterogeneous one as will be seen later.

Consider a simple panel-data model with a first-order autoregressive component,

$$
y_{i t}=\rho_{i} y_{i, t-1}+\delta_{i} X_{i t}^{\prime}+\epsilon_{i t}
$$

Where $i=1, \ldots, N$ indexes panels; $t=1, \ldots, T$ indexes time; $y_{i t}$ is the variable being tested; and $\epsilon_{i t}$ is a stationary error term that is assumed to be mutually independent idiosyncratic disturbance. The $X_{i t}$ term can represent panelspecific means only or panel-specific means and a time trend, or nothing.

Panel unit-root tests are used to test the null hypothesis $\mathrm{H}_{0}$ : $\rho_{i}=1$ for all $i$ versus the alternative $\mathrm{H}_{a}: \rho_{i}<1$. Depending on the test, $\mathrm{H}_{\mathrm{a}}$ may hold, for one $i$, a fraction of all $i$ or alli; the output of the respective test precisely states the alternative hypothesis.

\section{i. The Levin-Lin-Chu (LLC) test}

The starting point for the Levin-Lin-Chu (LLC) [29] test assumes the restriction that all panels share a common autoregressive parameter.

LLC augments the model with additional lags of the dependent variable so that $\mu_{i t}$ will be white noise with potentially heterogeneous variance across panels:

$$
\Delta y_{i t}=\alpha y_{i t-1}+\sum_{j=1}^{p} \beta_{i j} \Delta y_{i t-j}+\delta_{i} X_{i t}^{\prime}+\mu_{i t}
$$

With the assumption of having a common $(\alpha)=\rho-1$. The null and alternative hypotheses for the tests may be written as:

$$
H_{0}: \alpha=0 \text { vs } H_{1}: \alpha<1
$$

Under the null hypothesis, there is a unit root, while under the alternative, there is no unit root.

\section{ii. The Hadri Test}

The test of LLC so far takes the null hypothesis that the series contains a unit root. Classical statistical methods are designed to reject the null hypothesis only when the evidence against the null is sufficiently overwhelming. Yet, the Hadri (2000) [18] LM test uses panel data to test the null hypothesis that the data are stationary versus the alternative that at least one panel contains a unit root. The test is designed for cases with large $\mathrm{T}$ and moderate $\mathrm{N}$.

The Hadri test is based on the residuals from the individual 
OLS regressions of $y_{i t}$ on a constant, or on a constant and a trend. For example, if we include both the constant and a trend, then the estimates are derived from;

$$
y_{i t}=r_{i t}+\beta_{i t}+\epsilon_{i t}
$$

Where $r_{i t}$ is a random walk;

$$
r_{i t}=r_{i t-1}+u_{i t}
$$

and $\epsilon_{i t}$ and $u_{i t}$ are zero-mean i.i.d. normal errors. Then, if the variance of $u_{i t}$ was zero, then $r_{i t}$ would collapse to a constant and $y_{i t}$ would therefore be trend stationary. Using this logic, the Hadri LM test tests the following hypothesis:

$$
H_{0}=\lambda=\frac{\sigma_{u}^{2}}{\sigma_{\epsilon}^{2}}=0 \text { Vs. } H_{0}=\lambda>0
$$

\section{iii. Harris-Tsavalis (HT) Test}

Harris-Tsavalis test (1999) [21] is based on the simple assumption that all panels share the same autoregressive parameter so that $\rho_{i}=\rho$ for alli. The HT test assumes that the number of time periods, $T$, is fixed, whereas $N$ tends to infinity. The HT test is suitable for micro panel where the time dimension, $T$, is small.

The HT test statistic is established based on the OLS estimator, $\rho$, in the regression model:

$$
y_{i t}=\rho y_{i, t-1}+\delta_{i} X_{i t}^{\prime}+\epsilon_{i t}
$$

Where the term $\delta_{i} X^{\prime}{ }_{i t}$ allows for panel specific means and trends. It is assumed that $\epsilon_{i t}$ is independent and identically distributed (i.i.d) normal with constant variance across panels. Harris and Tsavalis obtained the mean and standard error of $\hat{\rho}$ for (14) under the null hypothesis

$\mathrm{H}_{0}: \rho=1$ when neither panel-specific means nor time trends are included.

Table 4 presents the employed first-generation panel unit root tests which are conducted for the "intercept" specifications after allowing for the lag order of only according to MBIC criterion. This is also convenient due to data limitations and small number of observations. As can be seen in table, the HT (1999) [21] test fails to reject the null hypothesis of the unit root for the following variables at level at the 5\%; LNRE, LRE, LFD and LTO while it was able to reject the null hypothesis for the LPRGDP and $\mathrm{LPCO}_{2}$. Additionally, the Hadri test rejects the null hypothesis of stationarity for all of the variables at the $5 \%$ level of significance. When taking the first difference for the variables suffering from unit root at level for both tests, the variables turned to be stationary at the fits difference at the $5 \%$ significance level.

The LLC test, on the contrary, rejects the null hypothesis at level for all of the variables except for the LRE. This the LLC (2002) [29] contradict with the results of Hadri (2000) [18] and HT (1999) [21] rejecting the null hypothesis al level and confronting that the variable are stationary at level except for the LRE.

Accordingly and relying more on the HT test being more appropriate for the characteristics of this panel data, it can be concluded that most of the variables tests are stationary at the

\begin{tabular}{|c|c|c|c|c|c|c|}
\hline & LLC & & Hadri & & HT & \\
\hline Variables & Level & $\Delta$ & Level & $\Delta$ & Level & $\Delta$ \\
\hline LPRGDP & $-11.1416(0.0000)^{* *}$ & - & $8.3355(0.0000)$ & $-2.2622(0.9882) * *$ & $0.4534(0.0003) * *$ & - \\
\hline $\mathrm{LPCO}_{2}$ & $-4.5417(0.0000) * *$ & - & $6.6017(0.0000)$ & $-0.9126(0.8193) * *$ & $0.5257(0.0057) * *$ & - \\
\hline LNRE & $-3.0648(0.0011) * *$ & - & $12.1315(0.0000)$ & $-1.8269(0.9661) * *$ & $0.7503(0.6137)$ & $-0.1818(0.0000) * *$ \\
\hline LRE & $-0.8062(0.2101)$ & $-7.1970(0.0000) * *$ & $12.7280(0.0000)$ & $-0.0519(0.5207) * *$ & $0.7404(0.5653)$ & $-0.0692(0.0000) * *$ \\
\hline LFD & $-3.1036(0.0010) * *$ & - & $14.6636(0.0000)$ & $1.3631(0.0864) * *$ & $0.8330(0.9080)$ & $-0.1365(0.0000) * *$ \\
\hline LTO & $-2.8118(0.0025) * *$ & - & $12.8206(0.0000)$ & $1.3243(0.0927) * *$ & $0.8591(0.9513)$ & $0.0667(0.0000) * *$ \\
\hline
\end{tabular}
first difference at the $5 \%$ significance level. This should lead to test for co-integration.

Table 4. First Generation Panel Unit Root Tests; The HT (1999), LLC (2002) and Hadri (2000).

1) $* * *, * *$ and $*$ denotes statistical significance at the $1 \%, 5 \%$ and $10 \%$ levels respectively.

2) The lambda-statistics and the standardized Z-bars are reported for the Breitung (2000) and Pesaran (2007) unit root tests, respectively; p-values in parentheses; the null hypothesis for all tests is "Panels contain unit roots".

\subsubsection{Panel Co-integration Analysis}

The application of cointegration examination is of significance particularly when managing non-stationary variables that may assume the presence of long run relationship.

i. Kao- Panel Cointegration Test

Considering a general panel data model as;

$$
y_{i t}=\dot{x}_{i t} \beta+Z^{\prime}{ }_{i t} \gamma_{i}+e_{i t}
$$

Kao (1999) [27] tests assume a cointegrating vector that is the same across all panels, which restricts $\beta_{i}=\beta$ in (15). However, Kao tests estimate panel-specific means and do not permit for a time trend, $\operatorname{so}(z)$ from (15) is always a vector of 1 's for Kao tests and $y_{i t}$ and $\dot{x}_{i t}$ are I (1) and non - cointegrated. This yields the cointegrating relationship;

$$
y_{i t}=\dot{x}_{i t} \beta+\gamma_{i}+e_{i t}
$$

Where $\gamma_{i}$ denotes panel-specific means (fixed effects) and $\beta$ is the same cointegrating vector. The null hypothesis of the Kao test is the absence of cointegration among the series. The alternative hypothesis assumes that the series in all panels are cointegrated with the same cointegrating vector.

ii. Westerlund (2005) Test

For the null hypothesis of no cointegration, Westerlund (2005) [49] derives a Variance Ratio test statistic. By default, the model uses an AR parameter that is panel specific as in (17) and the alternative hypothesis is that the series in some 
of the panel countries are cointegrated.

$$
y_{i t}=\dot{x}_{i t} \beta_{i}+Z^{\prime}{ }_{i t} \gamma_{i}+e_{i t}
$$

However, the possibility of restricting the AR parameter to be common across all the panel countries is provided in the alternative hypothesis. Specifically, the alternative hypothesis in this latter case restricts the $\left(\rho_{i}=\rho\right)$ in (18):

$$
\hat{e}_{i t=} \rho_{i} \hat{e}_{i t-1}+v_{i t}
$$

In fact, Westerlund presume that all of the panel countries are having individual slope coefficients and hence expect a panel-specific cointegrating vectors as in (17). The VR test statistics are calculated through examining for a unit root in the predicted residuals using the DF regression as specified in (18).

Table 5. First Generation Panel Co-integration Tests

\begin{tabular}{lll}
\hline Test & Kao (1999) & Westerlund (2005) \\
\hline ADF $_{t}$ & $-0.4588(0.3232)$ & - \\
Modified DF & $-0.4123(0.3400)$ & - \\
DF t & $-2.2078(0.0136)$ & - \\
VR & - & $0.3268(0.3719)$ \\
\hline
\end{tabular}

Notes:(1) The null hypothesis is no co-integration versus the alternative one that assumes the same AR parameter across all panels, (2) The tests for cointegration are performed using the Stata "xtcointtest" command,(3) serial correlation tests has been conducted through the Stata command "xtserial" where autocorrelation has been found to be present at the $5 \%$ significance level and thus the unadjusted DF $t$ and unadjusted modified DF $t$ can be excluded as they require no serial correlation,(4) statistics of the two tests have been selected based its relevant in case of common AR coefficient and applicability for endogenous regressors with serial correlation residuals.

Tables 5 shows the results of the first-generation panel cointegration assuming specification without a trend. As a matter of fact, it can be seen that the statistics both tests failed to reject the null hypothesis of no-cointegration at the $5 \%$ and $1 \%$ level of significance indicating the absence of cointegration among the panel units. Accordingly and having confirmed the absence of no-cointegration, then a PVAR analysis should be conducted with short run relationships are to be investigated only.

\subsubsection{Panel VAR Analysis}

In general, a dynamic relationship is characterized by the presence of a lagged dependent variable among the regressors. Assuming a basic model that includes only the variables of interest as the economic growth and disaggregated electricity generation variables,

$$
\begin{aligned}
& L Y_{i t}=\alpha_{0}+\lambda_{1,1} L Y_{i t-1}+\lambda_{1,2} L R E_{i t-1}+\lambda_{1,3} L N R E_{i t-1} \\
& +\beta X_{i t}+u_{i t} \\
& i=1, \ldots \ldots, N, t=1 \ldots ., T
\end{aligned}
$$

Where $i=1 \ldots, N$ (cross-sectional dimension) and $t=1 \ldots, T$ (time dimension). $\lambda_{1}$ Is a scalar; $Y_{i t}$ is a $(1 x k)$ vector of dependent variables, $X_{i t}$ is a $(1 x l)$ vector of exogenous covariates taking into consideration that the model of interest has no exogenous variables. In applying the
VAR procedure to panel data, there is a need to impose the restriction that the underlying structure is the same for each cross-sectional unit. However and in reality, this constraint is likely to be violated, thus, one way to overcome such a restriction on parameters is by allowing "individual heterogeneity" in the levels of the variables by introducing fixed effects, denoted by $\left(u_{i}\right)$ in the model.

Assuming that $u_{i t}$ consists of the following;

$$
u_{i t}=\mu_{i}+v_{i t}
$$

$u_{i t}$ is composed of the two error components $\mu_{i}$ as the unobservable individual effects and $v_{i t}$ is the remainder error term and $\mu_{i} \sim \operatorname{IID}\left(0, \sigma_{\mu}^{2}\right)$ and $v_{i t} \sim \operatorname{IID}\left(0, \sigma_{\mu}^{2}\right)$ independent of each other and among themselves.

In order to estimate the dynamic panel data regression described in (19) and (20), it can be found that it is characterized by two sources of persistence over time. First, is the autocorrelation stemming from the presence of a lagged dependent variable among the regressors. Second, is the individual effect characterizing the heterogeneity among the individuals. These two sources of persistence render different estimators to be inadequate in estimating the PVAR dynamic model and that's why the approach of Blundell \& Bond (1998) [9] which is known as 'system' GMM (SYSGMM) is going to be used which makes use of both 'level' and 'difference' GMM.

Despite what its name implies, a 'system' GMM, deals with the data system as a single-equation problem since the same linear functional relationship is believed to apply in both the transformed and untransformed variables as:

$$
\left(\begin{array}{c}
\Delta y \\
y
\end{array}\right)=\alpha\left(\begin{array}{c}
\Delta y_{t-1} \\
y_{t-1}
\end{array}\right)+\beta\left(\begin{array}{c}
\Delta X_{t-1} \\
X_{t-1}
\end{array}\right)+\left(\begin{array}{c}
\Delta u \\
u
\end{array}\right)
$$

The system GMM eliminate the fixed effect through some kind of transformation other that differencing called 'forward mean differencing or orthogonal deviations' (the Helmert procedure). In this procedure, to remove the fixed effects, all variables in the model are transformed in deviations from forward means.

Let $y_{i t}^{m}$ and $u_{i t}^{m}$ denote a variable and an error term, respectively in two vectors;

$$
y_{i t}=\left(y_{i t}^{1}, y_{i t}^{2} \ldots \ldots, y_{i t}^{M}\right)
$$

and

$$
e_{i t}=\left(e_{i t}^{1}, e_{i t}^{2}, \ldots \ldots ., e_{i t}^{M}\right)
$$

The means obtained from the future values of $y_{i t}^{m}$ and $u_{i t}^{m}$ are equal to;

$$
\begin{aligned}
\bar{y}_{i t}^{m} & =\sum_{s=t+1}^{T_{i}} \frac{y_{i s}^{m}}{\left(T_{i-1}\right)} \\
\bar{u}_{i t}^{m} & =\sum_{s=t+1}^{T_{i}} \frac{u_{i s}^{m}}{\left(T_{i-1}\right)}
\end{aligned}
$$

Where $T_{i}$ is the last period of data available for a given country series. The transformed variable and error term can be written as: 


$$
\tilde{y}_{i t}^{m}=\delta_{i t}\left(y_{i t}^{m}-\bar{y}_{i t}^{m}\right)
$$

And

$$
\tilde{u}_{i t}^{m}=\delta_{i t}\left(u_{i t}^{m}-\bar{u}_{i t}^{m}\right)
$$

Where,

$$
\delta_{i t}=\sqrt{\frac{T_{i-t}}{T_{i-t+1}}}
$$

However, the last year of data cannot be calculated, this is because there are no future values for the construction of the forward means. This transformation is in fact an orthogonal deviation in the sense that each observation is expressed as a deviation from average future observations. According to Roodman (2009) [40], one advantage of the forward means differencing over the first-difference procedure is that it has the virtue of preserving sample size in panels with gaps. The first-difference procedure has the deficiency of magnifying gaps in unbalanced panels. This technique enables the use of lagged values of regressors as instruments. Then, the transformed model becomes:

$$
\tilde{y}_{i t}=\alpha_{1} \tilde{y}_{i t}+\tilde{e}_{i t}
$$

Where

$$
\tilde{y}_{i t}=\left(\tilde{y}_{i t}^{1}, \tilde{y}_{i t}^{2}, \ldots \ldots, \tilde{y}_{i t}^{M}\right)
$$

And

$$
\begin{aligned}
& \tilde{u}_{i t}^{m}=\left(\tilde{u}_{i t}^{1}, \tilde{u}_{i t}^{2}, \ldots \ldots ., \tilde{u}_{i t}^{M}\right)^{\prime} \\
& \mathrm{L} \widetilde{Y}_{i t}=\sum_{j=1}^{p} \lambda_{1,1 j} L \tilde{C}_{i t-j}+\sum_{j=1}^{p} \lambda_{1,2 j} L \widetilde{R E}_{i t-j}+\sum_{j=1}^{p} \lambda_{1,3 j} L \widetilde{N R E}_{i t-j}+ \\
& \sum_{j=1}^{p} \lambda_{1,4 j} L \widetilde{F D}_{i t-j}+\sum_{j=1}^{p} \lambda_{1,5 j} L \widetilde{T O}_{i t-j}+\sum_{j=1}^{p} \lambda_{1,6 j} \widetilde{L Y_{l t-j}}+\varepsilon_{1 i t} \\
& \mathrm{~L} \tilde{C}_{i t}=\sum_{j=1}^{p} \lambda_{2,1 j} L \tilde{C}_{i t-j}+\sum_{j=1}^{p} \lambda_{2,2 j} \widetilde{L R E_{l t-j}}+\sum_{j=1}^{p} \lambda_{2,3 j} L \widetilde{L N E_{l t-\jmath}}+ \\
& \sum_{j=1}^{p} \lambda_{2,4 j} L \widetilde{F D}_{i t-j}+\sum_{j=1}^{p} \lambda_{2,5 j} L \widetilde{T O}_{i t-j}+\sum_{j=1}^{p} \lambda_{2,6 j} L \tilde{Y}_{i t-j}+\tilde{\varepsilon}_{2 i t} \\
& \mathrm{LRE}_{i t}=\sum_{j=1}^{p} \lambda_{3,1 j} \widetilde{L C}_{i t-j}+\sum_{j=1}^{p} \lambda_{3,2 j} \widetilde{L R E_{i t-j}}+\sum_{j=1}^{p} \lambda_{3,3 j} \stackrel{L N R E_{l t-j}}{ }+ \\
& \sum_{j=1}^{p} \lambda_{3,4 j} L \widetilde{F D}_{i t-j}+\sum_{j=1}^{p} \lambda_{3,5 j} L \widetilde{T O}_{i t-j}+\sum_{j=1}^{p} \lambda_{3,6 j} \widetilde{L Y_{l t-J}}+\widetilde{\varepsilon}_{3 i t} \\
& \widetilde{L N R E}_{i t}=\sum_{j=1}^{p} \lambda_{4,1 j} \widetilde{L C}_{i t-j}+\sum_{j=1}^{p} \lambda_{4,2 j} \widetilde{L R E}_{i t-j}+\sum_{j=1}^{p} \lambda_{4,3 j} \widetilde{L N R}_{i t-j}+ \\
& \sum_{j=1}^{p} \lambda_{4,4 j} \widetilde{L F D}_{i t-j}+\sum_{j=1}^{p} \lambda_{4,5 j} L \widetilde{T O}_{i t-j}+\sum_{j=1}^{p} \lambda_{4,6 j} L \tilde{Y}_{i t-j}+\tilde{\varepsilon}_{4 i t} \\
& \widetilde{L F D}_{i t}=\sum_{j=1}^{p} \lambda_{5,1 j} \widetilde{L C}_{i t-j}+\sum_{j=1}^{p} \lambda_{5,2 j} \widetilde{L R E_{i t-j}}+\sum_{j=1}^{p} \lambda_{5,3 j} \widetilde{L N R E}_{i t-j}+ \\
& \sum_{j=1}^{p} \lambda_{5,4 j} \widetilde{L F D}_{i t-j}+\sum_{j=1}^{p} \lambda_{5,5 j} \widetilde{L T O_{i t-j}}+\sum_{J=1}^{p} \widetilde{\lambda_{5,6 J}} L Y_{l t-\jmath}+\widetilde{\varepsilon}_{5 i t} \\
& \widetilde{\mathrm{LTO}}_{i t}=\sum_{j=1}^{p} \lambda_{6,1 j} \widetilde{L C}_{i t-j}+\sum_{j=1}^{p} \lambda_{6,2 j} \widetilde{L R E_{i t-j}}+\sum_{j=1}^{p} \lambda_{6,3 j} \widetilde{L N R}_{i t-j}+ \\
& \sum_{j=1}^{p} \lambda_{6,4 j} \widetilde{L F D}_{i t-j}+\sum_{j=1}^{p} \lambda_{6,5 j} L \widetilde{T O}_{i t-j}+\sum_{j=1}^{p} \lambda_{6,6 j} \widetilde{L Y_{l t-j}}+\tilde{\varepsilon}_{6 i t}
\end{aligned}
$$

Throughout the equations from (28) to (38), $(t)$ denotes the time period dimension of the panel, $(i)$ denotes the crosssectional dimension and the $(\sim)$ refers to the variables after being transformed through the forward orthogonal deviation.

To the best of my knowledge, this kind of investigation has not been done until the date of the day for the case of MENA 
countries and this study is the first one that uses PVAR approach in a system GMM framework for this selected panel countries. The advantage of this technique is that it combines the traditional VAR approach, which treats all the variables in the system as endogenous, with the panel-data approach, which allows for unobserved individual heterogeneity.

Table 6. PVAR Results.

\begin{tabular}{|c|c|c|c|c|c|c|}
\hline \multirow{2}{*}{$\begin{array}{l}\text { Dependent } \\
\text { variables } \\
\end{array}$} & \multicolumn{6}{|c|}{ Independent variables } \\
\hline & D_LPRGDP (-1) & $\mathrm{D} \_L P C O_{2}(-1)$ & D_LRE (-1) & D_LNRE (-1) & D_LFD (-1) & D_LTO (-1) \\
\hline D_LPRGDP & $-.2239192(0.000) * *$ & $-.3481133(0.000) * *$ & $-.058769(0.000) * *$ & $.0081412(0.566)$ & $.0670748(0.011) * *$ & $.0556065(0.027) * *$ \\
\hline $\mathrm{D}_{-} \mathrm{LPCO}_{2}$ & $-.0085429(0.833)$ & $-.0126164(0.753) * *$ & $-.0461941(0.000) * *$ & $.0849947(0.000) * *$ & $-.0992133(0.003) * *$ & $-.1191776(0.002) * *$ \\
\hline D_LRE & $.5051563(0.005) * *$ & $1.386058(0.000) * *$ & $-.0615078(0.030) * *$ & $-.2568856(0.015) * *$ & $1.047762(0.000) * *$ & $-1.038242(0.000) * *$ \\
\hline D_LNRE & $-.0111609(0.806)$ & $-.279591(0.000) * *$ & $-.0248129(0.003) * *$ & $-.0980391(0.043) * *$ & $-.0312093(0.453)$ & $.3728356(0.000) * *$ \\
\hline D_LFD & $.387124(0.000) * *$ & $.6224109(0.000) * *$ & $.0673821(0.000) * *$ & $.0696267(0.033) * *$ & $.2780965(0.000) * *$ & $-.0956041(0.042) * *$ \\
\hline D_LTO & $.3246087(0.000) * *$ & $-.3136933(0.000) * *$ & $.0013092(0.867)$ & $.0332043(0.047) * *$ & $.1021877(0.001) * *$ & $.1910496(0.000) * *$ \\
\hline
\end{tabular}

Notes: The six-variable VAR model is estimated by SYS- GMM; country-specific and fixed effects are removed prior to estimation. Heteroscedasticity and serial correlation robust standard errors are in brackets. $* * *, * * *$ denote test statistical significance at the $1 \%, 5 \%$ and $10 \%$ levels, respectively. All variables are in logs and Helmert transformed before estimation. Stability of the model has been examined and confirmed.

Based on the achieved results in table 6, equation (28), the estimates while show a positive relationship between economic growth and NRE it shows on the contrary an inverse relationship between former and the RE. The coefficient of the RE shows a negative and significant relationship at the 5 per cent level. It indicates that a 1 percent increase in electricity generation from renewable sources reduces the PRGDP by 0.058 percent. Having such a negative effect implies that the policies supporting the renewable energy industry in the MENA countries are not having still the desired expected results from its application. Increasing costs at such stage may have such negative impact on economic growth. It can be further studied in the future the effect of using renewable energy on the economic growth at some mature stge.

The negative relationship between both variables points to the presence of a tradeoff between them at the time being. This is because shifting investments towards renewables could entail lower investments in other sectors that boost growth.

This significant impact of RE on PRGDP while negative but offers a great opportunity in the future in meeting the rising energy demand of these countries. The rich endowment of renewable sources can cover such an increasing expansion in electricity generation and offers a cheaper way to increase the environment quality suggesting positive effect to be expected. However, these results are opposite to what Dees et al. (2018) [13] reached to where the study concluded a positive impact of renewable electricity generation on the economic growth for MENA countries despite the weak effect obtained for single countries. Different results can be attributed different variables used, different methodologies and different countries selected.

The effect of NRE on PRGDP although positive but insignificant. This means that the role of electricity generation in MENA countries is relatively small. According to Şenturk et al. (2016) [43], he found that for example electrical consumption in Turkey does not affect economic growth. Also, in Tunisia, Hedia (2015) [22] concluded that the energy sector played a decisive role in the social as well as the development of Tunisia recently, the Tunisian energy balance has registered a neat deficit. Also, for a panel of GCC countries, Asif et al. (2015) [5] found no statistical significant relationship between energy consumption and economic growth. Additionally, in a study for the energy consumption and economic growth in selected African countries, Raheem et al. (2015) [39] found that the relationship between energy consumption and economic growth for most of the included countries was insignificant. This study advocated that the inability of some countries in the panel like Egypt and Tunisia to achieve high rates of economic growth is due to the infrastructures and facilities being aged old fashioned ones and because of the inefficiency and overburden which lead to constant breaks.

Both of FD and TO have positive significant impact on PRGDP and thus more TO and FD stimulate more growth. This indicates that an increase in financial development tends to promote economic growth and such effect is highly significant at the 1 per cent level. This could shed the light on how important the financial development in these countries are for their growth and how important the loans to these countries are. These results are in line with Omri et al. (2015) [34] who found that FD as well as TO positively and significantly affect the PRGDP of the MENA countries. It can be concluded that both variables are having an inelastic effect with respect to the economic growth which refers to their important impact on the growth of these countries.

Per capita $\mathrm{CO}_{2}$ emissions negatively and significantly affect the per capita GDP at the level of significance where for every increase in $\mathrm{PCO}_{2}$ emissions, economic growth decreases by $0.34 \%$. this means that the more is the environmental degradation, the lower will be the economic growth. This is because of the harmful effect of pollution that cause to the whole society and affecting people's health which eventually can affect their level of production and hence economic growth. This finding is in contrast to the results of Muhammad, B., 2019 [31] who found a positive and significant effect for the $\mathrm{PCO}_{2}$ emissions on the economic growth of MENA countries for the period of $2001-2017$.

Equation (29), holds an important relationship regarding the environment quality expressed by $\mathrm{PCO}_{2}$ emissions. Both of the RE and NRE are having a significant impact on the 
$\mathrm{PCO}_{2}$ but with different signs. NRE a positively influence $\mathrm{PCO}_{2}$ emissions while a negative relationship is found with regard to the RE. Thus, considering the environmental effect of both sources of energy it can be shown that increases in $\mathrm{RE}$ sources contribute to the reduction of $\mathrm{PCO}_{2}$ and mitigate the level of emissions even given its small impact. It can be seen that a $1 \%$ increase in renewable electricity generation can reduce the $\mathrm{PCO}_{2}$ emissions by 0.046 percent, whereas a $1 \%$ rise in NRE boosts the level of emissions by 0.085 per cent. These results recommend the fact that RE prompt some sort of enhancements in the environment keeping it clean whereas the NRE prompts environment corruption. These results are being steady with the state of art proposing that renewable electricity generation prompts natural enhancements while non-renewable generation prompts ecological corruption.

The significance of the RE regarding both the $\mathrm{PCO}_{2}$ and the PRGDP in this region, means that this variable is highly effective regarding this panel, Yet, it's still of a little use due to its high expensive infrastructure costs. However, this shed the light on how important such a variable is and encourages the more use of it hoping to reap its fruits in the future.

The positive relationship between the $\mathrm{FD}$ and $\mathrm{PCO}_{2}$ indicates that financial development in MENA countries are taking place while taking into consideration the issues of environmental degradation and hence is occurring through the use of clean forms of electricity. Tamazian et al. (2009) [46] revealed that financial development can enhance economic growth and at the same time reduces $\mathrm{CO}_{2}$ emissions like how it occurred in the BRICS countries over the period 1992-2004. Accordingly, while FD is found to significantly stimulating the more economic growth, it at the same time occurs not at the expense of environmental quality.

The elasticity of trade openness with respect to $\mathrm{PCO}_{2}$ is negative and significant. This negative relation between the $\mathrm{PCO}_{2}$ emissions and trade openness indicates that the MENA counties had to some extent perceived the importance of using friendly environmentally techniques in importing and exporting goods. Also, such results indicate these countries had to develop the use of clean energy among its factors of production and inputs. This significant effect plays a role in increase the welfare of these countries in the long run and this also can be backed by the positive impact that trade openness has on the PRGDP. These results are different from Omri et al. (2015) [34] who found that an increase in foreign trade to GDP ratio results in an increase in per capita $\mathrm{CO}_{2}$ emissions. However, the achieved results are in line with Muhammad, B., 2019 [31] who also found that trade openness has a negative and significant effect on the $\mathrm{CO}_{2}$ emissions.

Finally, the economic growth has a negative and insignificant effect on per capita $\mathrm{CO}_{2}$ emissions. Such results are in line with Muhammad, B., 2019 [31] who found, according to the difference GMM estimator, that the economic growth has a negative and non-significant relationship with $\mathrm{CO}_{2}$ emissions.

Equations (30) and (31) holds by far the most important relations for the panel concerned with the disaggregated energy sources effect on the other variables. A positive and significant relationship between the PRGDP and RE is found where as a negative insignificant relationship between PRGDP and NRE is concluded. The results indicate that a 1 per cent increase in PRGDP leads to 0.51 per cent increase in $\mathrm{RE}$ and a 0.01 per cent decrease in the NRE. These results are very important and unique in terms of the effect of economic growth on the NRE. This is because where Kahia et al. (2016) [24] found a significant positive impact of economic growth on both of RE and NRE consumption, the results here found insignificant impact of GDP on NRE.

Such a conclusion of the positive impact of economic growth on RE indicates that these countries are paying more attention to the development of RE projects and are taking empirical steps to execute renewable electricity generation projects and have it as an integral part of the total electricity generated.

In addition, when $\mathrm{PCO}_{2}$ emissions increase, the use of NRE decrease which points to the idea that these counties start to decrease the dependence on non-renewable sources as carbon emissions increase and at the same time raises the use of the RE sources and are aware of their effect on decreasing such emissions leading to more environmental quality.

As for the elasticity of RE with respect to NRE and the opposite, it can be seen that a $1 \%$ increase in RE generation can decrease the generation of NRE by 0.024 percent which suggests that the two sources of electricity can be seen as being substitutes. On the other hand, a $1 \%$ increase in the NRE reduces the use of the RE by 0.25 per cent confirming also the substitutability between the two sources of electricity. But it should be taken into consideration that the increasing use of NRE affect negatively the RE more than an increase in the RE does on the NRE. This means that the non-renewable electricity generation still have a dominant effect more that the RE does.

This means as previously mentioned that the MENA countries still have a long way to maintain the RE as a reliable source of energy. Kahia et al. (2016) [24] found no significant effect of one type of energy on the other in the short run.

Regarding equation (32), analyzing the relationship between RE, NRE and financial development. It can be seen that both sources of electricity positively and significantly affect the FD and has the same magnitude as well. A $1 \%$ increase in both RE and NRE would stimulate an increase in FD by $0.067 \%$ and $0.069 \%$ respectively. Such results are very important as it shed the light on the equality of achievement between these two sources in enhancing the financial development in these countries and that any substitution between these two sources won't harm the FD.

The panel result shows that PRGDP has a positive and significant impact on financial development. This entails that increases in economic growth do enhance the level of financial development where a 1 per cent increase in PRGDP leads to an increase in the FD by PRGDP by 0.38 per cent.

As for equation (33), for the relationships between trade 
openness and PRGDP, it can be found that a $1 \%$ increase in economic growth raises the trade openness by $0.32 \%$. In addition to, it can be noticed that it is only the non-renewable electricity generation that affect trade openness not the RE. This can justify also the negative relationship between the trade openness and $\mathrm{PCO}_{2}$ where the more trade as a percentage of GDP, the more is the environmental degradation.

Summing up, this paper results suggest that MENA countries do not gain from investments in renewables with regard to economic growth. However, investing in renewables do enhance the environmental quality and works on reducing it while at the same time boosts financial development. This may well encourage the governments in the region to proceed and escalate approaches that enhance the utilization of renewables, as the potential for renewable vitality arrangement within the MENA is gigantic. Such conclusion is similar to that of Kahia et al.(2019) [26] who found that renewable energy, international trade and foreign direct investment inflows lead to reductions in carbon dioxide emissions. They advocated that "A serious shift toward using more renewable energy resources, international trade and foreign direct investment inward is recommended to improve the environmental quality and attain the sustainable growth in the region".

To upgrade the positive impacts on economic growth and development, policy-makers ought to effectively utilize industrial policy tools that would benefit from investments in renewables and to extend innovation exchange, making openings for spillover impacts on the economy. However, estimation of these impacts remains challenging due to accessible data being available. Hence, more in-depth investigations at country-level are required where these impacts can be specified more accurately.

\subsubsection{Panel Granger Causality Analysis}

In panel work file settings, panel data causality testing is applied using least squares regression. The short-run causal relationships are being investigated using the lagged differences of the variables specified in each equation. To check for the direction of the short-run causality between variables, we run the pairwise Granger causality tests. These tests are exploited to analyze and examine the way of shortrun causality between variables in pairs. Direct and indirect causal relationships in the short run can be deuced from such Granger causality tests.

The causality tests seek to explore if changes in $x$ cause changes in $y$. This infers that if $x$ causes $\mathrm{y}$ then this implies lags of $x$ should be critical in equation for $y$. In this case, it is said that $x$ Grangercauses $y$ "or have a unidirectional causality relationship from $x$ to $y$. The case is the same for $y$ in the event that it causes $x$. When the two arrangements of lags are noteworthy and significant, then this implies that a bidirectional causality or feedback exists between the two variables. At that point, the essential idea in the Granger causality is to see the amount of the current variable that can be clarified by past values of the other explanatory variables.
This procedure restricts that all coefficients to be the same over each and every cross-segment According to model (1), results can be seen as in table 7 .

Empirical results demonstrate that a bidirectional feedback causal relationship is found between the renewable electricity generations and economic growth whereas no causality was found between the non-renewable sources and economic growth. Thus for the case of renewables, this indicates that even though the low share of the renewables in the electricity generation mix of these countries but still its role is important and fundamental regardless its negative impact in the short run. Also, the causality running from economic growth to RE means that the RE sector in these countries is starting to gain more importance in their economies. This means that when the RE becomes a real substitute to the NRE, then it can help in attaining a higher rate of growth and development in these countries and helps in achieving and prompting higher rates economic growth.

On the other hand side, neutrality is confirmed between the NRE and economic growth. This conclusion can shed the light on the less importance of such sources of electricity in promoting more economic growth and that the achievement of more economic growth should not lead to the increasing usage of NRE sources As neutrality hypotheses has been confirmed during the period of study, then this can indicate that conserving electricity form NRE should not harm the economic growth of these countries and hence conservation policies won't be achieved at the expense of more economic growth. This also implies that polices aiming at achieving higher economic growth rates will not affect NRE. These results are in line with Gorus, M.S. and Aydin, M., (2019) [16] who fund that the energy conservation hypothesis holds the short run.

Hence, any energy conservation policies aimed at reducing NRE will not have negative impacts on economic growth. The same conclusion has been achieved by Ozturk et al. (2011) [36] who concluded that any conservation policy of MENA countries will have no powerful effect on the region economic growth. Nevertheless, this implies that the MENA countries have easy access to two options that help in reducing the $\mathrm{PCO}_{2}$ emissions without harming their economic growth. These are increasing the share of renewables in the electricity supply mix which they are rich endowed with along with a simultaneous reduction in the NRE that is becoming now to some extent a costly input after decreasing subsidizing it in some of the MENA countries after the Arab spring.

Moreover, $\mathrm{PCO}_{2}$ emissions are found to negatively cause the economic growth. This implies that the environmental and energy conservation policies which targets less carbon emissions will not only hurt or retard the economic growth but will also help in reducing carbon emissions, besides, structural policies, that targets increasing global economic growth, should improve the quality of the environment. These results are similar to that of Gövdeli, T., (2019) [17] who found a unidirectional causality from $\mathrm{CO}_{2}$ emissions to economic growth. Gövdeli, T., (2019) [17] pointed out that 
"These countries need to better implement environmental policies and take measures to reduce $\mathrm{CO}_{2}$ emissions where situations that will negatively affect economic growth should be avoided while reducing $\mathrm{CO}_{2}$ emissions".

Additionally, a bidirectional causality relationship is found to be significant at the 5 percent level between both sources of electricity and the $\mathrm{PCO}_{2}$ emissions. Such a conclusion can serve as an important indictor to the importance of renewable electricity generation in predicting lower emissions of $\mathrm{CO} 2$ in the future and also highlights the gravity of increasing the use of non-renewable sources of electricity in estimating higher levels of $\mathrm{CO}_{2}$. These results are similar to Gorus, M.S. and Aydin, M., (2019) [16] who confirmed the presence of a feedback effect between energy consumption and emission level in the intermediate- and the long-run for the period of (1975-2014). Kahia et al. (2019) [26] found also a bidirectional causality between the renewable energy and $\mathrm{CO}_{2}$ emissions for a panel of selected MENA countries over the period of 1980-2012. They concluded that such a casualty implies that the renewable energy deployment can effectively improve the environmental quality and that harmful changes in $\mathrm{CO}_{2}$ emissions cause the increase in renewable energy use.

Nevertheless, economic growth doesn't cause carbon emissions or non-renewable electricity generation. This suggests that structural policies aiming at increasing economic growth in the MENA region will not impact NRE or causes any degradation to the environment.

Also, a bidirectional causality relationship is found to be significant at the 5 percent level between both economic growth and financial development supporting the feed-back hypothesis. Besides, when the dependent variable is $\mathrm{PCO}_{2}$, a bi-directional causality can be inferred to be running from both of financial development and trade openness to $\mathrm{PCO}_{2}$ emissions and significant at the 5 percent level. This means that the investments in these countries as well as openness to the external world support the using of the more advanced and clean technology that helps in lessening the $\mathrm{CO}_{2}$ emissions and help in energy and environmental conservations. The bidirectional causality result between $\mathrm{PCO}_{2}$ and TO is similar to that of Kahia et al. (2019) [26], who argued that more international trade is considered to be an efficient channel for distributing clean technologies that use renewable energy as a main source of production and that may participate in pollution reduction. Additionally, the bidirectional causality from FD and RE can support the previous results, in that FD in these counties act as a stimulus to the more use of $\mathrm{RE}$ and hence predicting lower levels of $\mathrm{PCO}_{2}$.

At the same instant, the two sources of electricity are found to have a bidirectional causality relationship so that the increase in one of them would result in predicating and estimating the less use of the other source given that they are having an inverse relationship. To end with, in the short-run, there is no direct granger causality relationship from was found from economic growth to $\mathrm{PCO}_{2}$ emissions, however a bidirectional causality can be detected through the RE, TO and FD.

From the above discussion, it can be noted that the PVAR estimates and the PVAR granger causality relationships are consistent. Such consistency confirms to some extent the explanation given above to the relationship between the variables under study.

Table 7. PVAR Granger Causality Tests.

\begin{tabular}{|c|c|c|c|c|c|c|}
\hline \multirow{2}{*}{ Dependent variable } & \multicolumn{6}{|c|}{ Chi-sq. (Probabilities) } \\
\hline & D_LPRGDP & $\mathrm{D}_{2} \mathrm{LPCO}_{2}$ & D_LRE & D_LNRE & D_LFD & D_LTO \\
\hline D_LPRGDP & - & $155.024(0.000) * *$ & $43.093(0.000) * *$ & $0.329(0.566)$ & $6.402(0.011) * *$ & $4.916(0.027) * *$ \\
\hline $\mathrm{D} \_L P C O_{2}$ & $0.045(0.833)$ & - & $37.772(0.000) * *$ & $17.324(0.000) * *$ & $8.624(0.003) * *$ & $9.640(0.002) * *$ \\
\hline D_LRE & $7.955(0.005) * *$ & $96.217(0.000) * *$ & - & $5.971(0.015) * *$ & $28.768(0.000) * *$ & $39.663(0.000) * *$ \\
\hline D_LNRE & $0.060(0.806)$ & $48.049(0.000) * * \mid$ & $9.094(0.003) * *$ & - & $0.562(0.453)$ & $44.120(0.000) * *$ \\
\hline D_LFD & $\left.69.919(0.000)\right|^{* *}$ & $174.392(0.000) * *$ & $49.534(0.000) * *$ & $4.539(0.033) * *$ & - & $4.119(0.042) * *$ \\
\hline D_LTO & $86.281(0.000) * *$ & $72.842(0.000) * *$ & $0.028(0.867) * *$ & $3.953(0.047) * *$ & $10.227(0.001) * *$ & - \\
\hline
\end{tabular}

Notes: (1) Values in parenthesis are the estimated p-values, $(2) * * *, * *$ and $*$ denotes statistical significance at the $1 \%, 5 \%$ and $10 \%$ levels respectively.

\section{Conclusion and Policy Implications}

The study explores the causal relationship between renewable electricity generation, nonrenewable electricity generation, carbon dioxide emissions per capita, financial development, trade openness and economic growth using time series data for 12 MENA countries over the period 2005-2014. The study found that there are no macroeconomic costs should be accompanied with the environmental and energy conservation policies targeting reducing carbon emissions and reducing fossil fuel electricity generation. However, renewable electricity generation is found to negatively impact the economic growth because of being still at primitive stage with heavy infrastructure costs.

Moreover, the two sources of electricity are confirmed to be substitutes to each other referring to the possibility of exchanging the RE for NRE at present with more efforts are to be done to boost economic growth. Nevertheless, both sources of electricity are founds to positively affect financial development while only the NRE positively and significantly affect trade openness.

Accordingly, the main policy implications suggested from this study is as follows; First, policies should be identified more to help in reducing the initial cost of investing in renewable energy projects and increase the investments efficiency in this field. This should be done in a way to restructure the generous subsidies given to the non-renewable energy sources and should be shifted to investments in renewable energy sources through helping investors in reducing their initial costs. Besides, suggestions are also 
made to support policies targeting the life cycle of renewable energy projects such as feed-in tariffs and power purchase agreements. These policies are more effective and less distortive than policies subsidizing the initial investment, such as cost reductions. Second, these countries should consider that more energy conservation policies aiming at reduce $\mathrm{CO}_{2}$ emissions will reduce economic growth. The research and investment in clean energy should be an integral part of the process of reducing the carbon dioxide emissions. Finally, Financial development and trade openness should be directed more to the usage of friendly environmentally technologies. This should help in improving the industrial sector by importing cleaner technology to attain maximum gain from international trade.

Despite trying to achieve the efficiency of the results obtained using the panel estimation technique the limitation of this study can be viewed in terms of concluding results and policy recommendations that are applicable at the regional levels but may probably not apply for individual countries. Accordingly, further studies should examine the causal relationship between disaggregated electricity sources, economic growth and carbon emissions using time series data.

\section{References}

[1] Aissa, M. S. B., Jebli, M. B. and Youssef, S. B., 2014. Output, renewable energy consumption and trade in Africa. Energy Policy, 66, pp. 11-18.

[2] Apergis, N. and Payne, J. E., 2010. The emissions, energy consumption, and growth nexus: evidence from the commonwealth of independent states. Energy policy, 38(1), pp. $650-655$.

[3] Andrews, D. W. and Lu, B., 2001. Consistent model and moment selection procedures for GMM estimation with application to dynamic panel data models. Journal of Econometrics, 101(1), pp. 123-164.

[4] Arouri, M. E. H., Youssef, A. B., M'henni, H. and Rault, C., 2012. Energy consumption, economic growth and $\mathrm{CO}_{2}$ emissions in Middle East and North African countries. Energy policy, 45, pp. 342-349.

[5] Asif, M., Sharma, R. B. and Adow, A. H. E., 2015. An empirical investigation of the relationship between economic growth, urbanization, energy consumption, and $\mathrm{CO}_{2}$ emission in GCC countries: a panel data analysis. Asian Social Science, $11(21)$, p. 270.

[6] Ben Jebli, M., Ben Youssef, S. and Ozturk, I., 2013. The environmental Kuznets curve: the role of renewable and nonRenewable energy consumption and trade openness.

[7] Bölük, G. and Mert, M., 2014. The Renewable Energy and Growth: Evidence for Turkey using Environmental Kuznets Curve Model. In The WEI International Academic Conference Proceedings, The West East Institute, Budapest, Hungary.

[8] Bond, S. R., Hoeffler, A. and Temple, J. R., 2001. GMM estimation of empirical growth models.
[9] Blundell, R. and Bond, S., 1998. Initial conditions and moment restrictions in dynamic panel data models. Journal of econometrics, 87(1), pp. 115-143.

[10] Breitung, J. and Das, S., 2005. Panel unit root tests under cross - sectional dependence. Statistica Neerlandica, 59(4), pp. 414-433.

[11] Breitung, J., 2001. The local power of some unit root tests for panel data. In Nonstationary panels, panel cointegration, and dynamic panels (pp. 161-177). Emerald Group Publishing Limited.

[12] Depuru, S. S. S. R., Wang, L. and Devabhaktuni, V., 2011. Electricity theft: Overview, issues, prevention and a smart meter based approach to control theft. Energy Policy, 39(2), pp. 1007-1015.

[13] Dees, P. and Vidican Auktor, G., 2018. Renewable energy and economic growth in the MENA region: empirical evidence and policy implications. Middle East Development Journal, 10(2), pp.225-247.

[14] Farhani, S. and Ben Rejeb, J., 2012. Energy consumption, economic growth and $\mathrm{CO}_{2}$ emissions: Evidence from panel data for MENA region. International Journal of Energy Economics and Policy (IJEEP), 2(2), pp. 71-81.

[15] Farhani, S. and Shahbaz, M., 2014. What role of renewable and non-renewable electricity consumption and output is needed to initially mitigate $\mathrm{CO}_{2}$ emissions in MENA region? Renewable and Sustainable Energy Reviews, 40, pp. 80-90.

[16] Gorus, M. S. and Aydin, M., 2019. The relationship between energy consumption, economic growth, and $\mathrm{CO}_{2}$ emission in MENA countries: Causality analysis in the frequency domain. Energy, 168, pp. 815-822.

[17] Gövdeli, T., 2019. $\mathrm{CO}_{2}$, quality of life and economic growth in mena countries. Cumhuriyet Üniversitesi İktisadi ve İdari Bilimler Dergisi, 20(1), pp. 281-292.

[18] Hadri, K., 2000. Testing for stationarity in heterogeneous panel data. The Econometrics Journal, 3(2), pp. 148-161.

[19] Halicioglu, F., 2009. An econometric study of $\mathrm{CO}_{2}$ emissions, energy consumption, income and foreign trade in Turkey. Energy Policy, 37(3), pp. 1156-1164.

[20] Hansen, L. P., 1982. Large sample properties of generalized method of moments estimators. Econometrica: Journal of the Econometric Society, pp. 1029-1054.

[21] Harris, R. D. and Tzavalis, E., 1999. Inference for unit roots in dynamic panels where the time dimension is fixed. Journal of econometrics, 91(2), pp. 201-226.

[22] Hedia, T., 2015. Relationship Between The Consumption of Electricity of Non-Renewable Origin and Economic Growth in Tunisia: Causality Analysis. In The 2015 WEI International Academic Conference Proceedings.

[23] Im, K. S., Pesaran, M. H. and Shin, Y., 2003. Testing for unit roots in heterogeneous panels. Journal of econometrics, $115(1)$, pp. 53-74.

[24] Kahia, M., Aïssa, M. S. B. and Charfeddine, L., 2016. Impact of renewable and non-renewable energy consumption on economic growth: New evidence from the MENA Net Oil Exporting Countries (NOECs). Energy, 116, pp. 102-115. 
[25] Kahia, M., Aïssa, M. S. B. and Lanouar, C., 2017. Renewable and non-renewable energy use-economic growth nexus: The case of MENA Net Oil Importing Countries. Renewable and Sustainable Energy Reviews, 71, pp. 127-140.

[26] Kahia, Montassar \& Ben Jebli, Mehdi \& Belloumi, Mounir., 2019. Analysis of the impact of renewable energy consumption and economic growth on carbon dioxide emissions in 12 MENA countries. Clean Technologies and Environmental Policy. 10.1007/s10098-019-01676-2.

[27] Kao, C., 1999. Spurious regression and residual-based tests for cointegration in panel data. Journal of econometrics, 90(1), pp. 1-44.

[28] Leitão, N. C., 2014. Economic growth, carbon dioxide emissions, renewable energy and globalization. International Journal of Energy Economics and Policy, 4(3), pp. 391-399.

[29] Levin, A., Lin, C. F. and Chu, C. S. J., 2002. Unit root tests in panel data: asymptotic and finite-sample properties. Journal of econometrics, 108(1), pp. 1-24.

[30] Maddala, G. S. and Wu, S., 1999. A comparative study of unit root tests with panel data and a new simple test. Oxford Bulletin of Economics and statistics, 61(S1), pp. 631-652.

[31] Muhammad, B., 2019. Energy consumption, $\mathrm{CO}_{2}$ emissions and economic growth in developed, emerging and Middle East and North Africa countries. Energy.

[32] Muhammad, S. S., Muhammad, Z. and Muhammad, S., 2011. Renewable and nonrenewable energy consumption, real GDP and $\mathrm{CO}_{2}$ emissions nexus: a structural VAR approach in Pakistan.

[33] Omri, A., 2013. $\mathrm{CO}_{2}$ emissions, energy consumption and economic growth nexus in MENA countries: Evidence from simultaneous equations models. Energy economics, 40, pp. 657-664.

[34] Omri, A., Daly, S., Rault, C. and Chaibi, A., 2015. Financial development, environmental quality, trade and economic growth: What causes what in MENA countries. Energy Economics, 48, pp. 242-252.

[35] Ozturk, F., 2017. Energy consumption-GDP causality in MENA countries. Energy Sources, Part B: Economics, Planning, and Policy, 12(3), pp. 231-236.

[36] Ozturk, I. and Acaravci, A., 2011. Electricity consumption and real GDP causality nexus: Evidence from ARDL bounds testing approach for 11 MENA countries. Applied energy, 88(8), pp. 2885-2892.

[37] Pesaran, M. H., 2004. General diagnostic tests for cross section dependence in panels.

[38] Pesaran, M. H., 2007. A simple panel unit root test in the presence of cross - section dependence. Journal of applied econometrics, 22(2), pp. 265-312.
[39] Raheem, I. D. and Yusuf, A. H., 2015. Energy consumptioneconomic growth nexus: evidence from linear and nonlinear models in selected African countries. International Journal of Energy Economics and Policy, 5(2), pp. 558-564.

[40] Roodman, D., 2008. Practitioners' corner. Oxford Bulletin of Economics and Statistics, 71(1), pp. 0305-9049.

[41] Sadorsky, P., 2010. The impact of financial development on energy consumption in emerging economies. Energy policy, 38(5), pp. 2528-2535.

[42] Sebri, M. and Ben-Salha, O., 2014. On the causal dynamics between economic growth, renewable energy consumption, $\mathrm{CO}_{2}$ emissions and trade openness: Fresh evidence from BRICS countries. Renewable and Sustainable Energy Reviews, 39, pp. 14-23.

[43] ŞENTÜRK, M. and Edgardo, S. I. C. A., 2016. Economic Growth and Energy Consumption in Turkey and Italy: A Frequency Domain Causality Analysis. Ömer Halisdemir Üniversitesi İktisadi ve İdari Bilimler Fakültesi Dergisi, 9(4), pp. 107-119.

[44] Shafiei, S. and Salim, R. A., 2014. Non-renewable and renewable energy consumption and $\mathrm{CO}_{2}$ emissions in OECD countries: A comparative analysis. Energy Policy, 66, pp. 547556.

[45] Spetan, A. A., 2016. Renewable energy consumption, $\mathrm{CO}_{2}$ Emissions and Economic growth: A case of Jordan. International Journal of Business and Economics Research, 5(6), pp. 217-226.

[46] Tamazian, A., Chousa, J. P. and Vadlamannati, K. C., 2009. Does higher economic and financial development lead to environmental degradation: evidence from BRIC countries. Energy policy, 37(1), pp. 246-253.

[47] Tiwari, A. K., 2011. Comparative performance of renewable and nonrenewable energy source on economic growth and $\mathrm{CO}_{2}$ emissions of Europe and Eurasian countries: A PVAR approach. Economics Bulletin, 31(3), pp. 2356-2372.

[48] Wesseh Jr, P. K. and Zoumara, B., 2012. Causal independence between energy consumption and economic growth in Liberia: Evidence from a non-parametric bootstrapped causality test. Energy Policy, 50, pp. 518-527.

[49] Westerlund, J., 2005. New simple tests for panel cointegration. Econometric Reviews, 24(3), pp. 297-316.

[50] Westerlund, J., 2007. Testing for error correction in panel data. Oxford Bulletin of Economics and statistics, 69(6), pp. 709748.

[51] Westerlund, J. and Edgerton, D. L., 2007. A panel bootstrap cointegration test. Economics letters, 97(3), pp. 185-190. 